\title{
Spectrophotometric Determination of Trace Amounts of Tungsten(VI) Based on Its Inhibitory Effect for the Red Intermediate Formation on the Iron(II) Catalyzed Chlorpromazine-Hydrogen Peroxide Reaction
}

\author{
Takashi TomIYASU and Norinobu YoNEHARA \\ Department of Chemistry, Faculty of Science, Kagoshima University, \\ Korimoto, Kagoshima 890, Japan
}

\begin{abstract}
A catalytic spectrophotometric method for the determination of traces of tungsten(VI) is proposed. In the presence of iron(II), chlorpromazine (CP) is oxidized by hydrogen peroxide in a hydrochloric acid solution to form a red free radical, which is further oxidized to a colorless compound. The reaction can be followed by measuring the increase in absorbance of the red free radical at $525 \mathrm{~nm}$; the maximum absorbance is obtained on an absorbance/time curve at a given reaction time. Tungsten(VI) inhibits the color formation and the maximum absorbance value decreases with an increase in the tungsten(VI) concentration. Thus, the maximum value is used as a parameter for the tungsten(VI) determination. Under the optimum experimental conditions $\left(7.6 \times 10^{-2} \mathrm{M}\right.$ hydrochloric acid, $4.9 \times 10^{-3} \mathrm{M}$ hydrogen peroxide, $2.5 \times 10^{-4} \mathrm{M}$ $\mathrm{CP}, 1.4 \times 10^{-4} \mathrm{M}$ iron(II), $35^{\circ} \mathrm{C}$ ), tungsten(VI) can be determined in the range from 2 to $500 \mu \mathrm{g} \mathrm{l}^{-1}$. The relative standard deviations are $0.7,0.2$ and $1.7 \%$ for 100,20 and $6 \mu \mathrm{g} \mathrm{l}^{-1}$, respectively. This method was successfully applied to a determination of tungsten(VI) in hot spring water samples.
\end{abstract}

Keywords Spectrophotometry, tungsten, chlorpromazine

Although some methods for the catalytic determination of tungsten(VI) have been proposed ${ }^{1-5}$, only a few methods are applicable for determining low levels of tungsten(VI) $\left(<10 \mu \mathrm{g} \mathrm{l}^{-1}\right)$ in aqueous solution..$^{3-5} \mathrm{~A}$ method, based on the tungsten(VI)-catalyzed redox reaction between Methyl Red and Ti(III) in a hydrochloric acid medium, was proposed by Jiang et al. ${ }^{3}$ Zhu et al. developed simultaneous determination of chromium(VI) and tungsten(VI) based on their catalytic effects on the reaction between hydrogen peroxide and iodide. ${ }^{4}$ These methods are sensitive, but are very susceptible to the influence of reaction conditions such as temperature and/or reaction time, because the reaction rate $^{4}$ or a parameter related to the rate (derivative peak current at a given reaction time) ${ }^{3}$ is measured.

Chlorpromazine (CP) is oxidized by hydrogen peroxide in an acidic solution by parallel pathways. 6,7 One of these is a direct colorless sulfoxide formation reaction, and can be followed by measuring the increase in absorbance at $344 \mathrm{~nm}$. The other pathway includes the formation of a red intermediate, which has been designated as being a free radical having an absorption maximum at $525 \mathrm{~nm}$ and is further oxidized to a colorless sulfoxide. Tomiyasu, one of the present authors, found that tungsten(VI) catalyzed the former pathway. $\mathrm{He}$ reported a catalytic spectrophotometric method for the determination of tungsten(VI). ${ }^{5}$ The method was high- ly sensitive and had a wide determinable range. However, since an initial reaction rate was used as a parameter, the method was very susceptible to the influence of reaction temperature. When the latter pathway of the oxidation of $\mathrm{CP}$ is followed by measuring the absorbance at $525 \mathrm{~nm}$, the absorbance increases with an increase in reaction time, and reaches a maximum value. After the absorbance maintains the maximum value for forty or fifty seconds the value decreases slowly. A considerable color formation is observed only in the presence of catalyst such as iron ion ${ }^{8}$ or iodide ${ }^{6}$, but in its absence the maximum absorbance value is rather low. We have observed that the maximum absorbance value is almost independent of temperature and that trace amounts of tungsten(VI) inhibited the catalyzed color formation reaction. If the maximum absorbance value was used as a parameter, a method having the advantage of a lack of influence of reaction temperature could be established. In the present study, we thus investigated the reaction conditions in detail and developed a convenient procedure for the catalytic determination of tungsten(VI), based on its inhibitory effect for the red intermediate formation on the iron(II) catalyzed CP-hydrogen peroxide reaction. The resulting method is both highly sensitive and reproducible with a calibration range of $2-500 \mu \mathrm{g} \mathrm{I}^{-1}$ based on the maximum-absorbance procedure. The variations of temperature have no 
effect on the tungsten(VI) determination in the range of $20-35^{\circ} \mathrm{C}$.

\section{Experimental}

\section{Apparatus and reagents}

A Japan Spectroscopic Co. Ubest-35 Spectrophotometer was used with a thermostated cell holder $\left(35 \pm 0.1^{\circ} \mathrm{C}\right)$ coupled with a Japan Spectroscopic Co. PTL3965 plotter. The temperature was controlled with a Shibata Science Instrument Co. control unit (CU-85) circulating thermostat bath. For the reaction, $1 \mathrm{~cm}$ glass cells were used. The reaction was initiated by the injection of a hydrogen peroxide solution from a Gilson Pipetman (Model P-200). For mixing, a remote-controlled magnetic Acrobat stirrer (MS Instrument, Osaka, Japan) was installed at the side of the cell holder in the spectrophotometer.

Pure water was prepared by purifying distilled water with a Millipore Milli-Q SP system just before use.

Reagent-grade chemicals were used throughout.

A CP solution $\left(3.6 \times 10^{-3} \mathrm{M}\right)$ was prepared by dissolving $0.128 \mathrm{~g}$ of chlorpromazine hydrochloride in water and diluting to $100 \mathrm{ml}$ with water.

A hydrogen peroxide solution $\left(4.9 \times 10^{-2} \mathrm{M}\right)$ was prepared by diluting $0.24 \mathrm{ml}$ of commercial $31 \%$ solution $(10.2 \mathrm{M})$ to $50 \mathrm{ml}$ with water.

A hydrochloric acid (1.0 M) solution was prepared by diluting a distilled hydrochloric acid $(6.1 \mathrm{M})$ with water.

An iron(II) solution $\left(2.0 \times 10^{-3} \mathrm{M}\right)$ was prepared by dissolving $0.157 \mathrm{~g}$ of ammonium iron(II) sulfate in $200 \mathrm{ml}$ of $0.1 \mathrm{M}$ hydrochloric acid.

A commercially available tungsten(VI) standard solution (1000 $\left.\mathrm{mg} \mathrm{1}^{-1}\right)$ was obtained from Wako. Working solutions were prepared by diluting this solution with water.

\section{Recommended procedure}

To a $10 \mathrm{ml}$ sample solution in a glass-stoppered tube, $1.0 \mathrm{ml}$ of $1.0 \mathrm{M}$ hydrochloric acid, $1.0 \mathrm{ml}$ of $3.6 \times 10^{-3} \mathrm{M}$ CP solution and $1.0 \mathrm{ml}$ of $2.0 \times 10^{-3} \mathrm{M}$ iron(II) solution were added and the components were thoroughly mixed. This solution was kept at $35^{\circ} \mathrm{C}$ in a water bath; a $1.8 \mathrm{ml}$ aliquot was then taken into a $1 \mathrm{~cm}$ glass cell. The cell was placed in the holder at $35^{\circ} \mathrm{C}$ and the contained solution was magnetically stirred. The reaction was initiated by the injection of $0.20 \mathrm{ml}$ of a $4.9 \times 10^{-2} \mathrm{M}$ hydrogen peroxide solution $\left(35^{\circ} \mathrm{C}\right)$. The increase in absorbance of the red intermediate at $525 \mathrm{~nm}$ was recorded against a pure-water reference.

\section{Results and Discussion}

The red intermediate formation reaction in the presence of iron(II) and the inhibitory effect of tungsten(VI)

Chlorpromazine (CP) is oxidized by hydrogen peroxide in an acidic solution to form colorless sulfoxide. In the presence of a catalyst such as iron, a red intermediate is formed, which is further oxidized to the colorless compound. The oxidation of CP to red intermediate is a reversible process ${ }^{9}$ and the red intermediate formation reaction can be followed by measuring the increase in the absorbance at $525 \mathrm{~nm}$. As can be seen in Fig. 1a, a trace amount of tungsten(VI) inhibits the iron(II)-catalyzed red intermediate formation reaction. In the absence of tungsten(VI), the absorbance increased with an increase in the reaction time, and reached a maximum value at a given time after adding the hydrogen peroxide solution (curve I). After the curves stayed at the maximum values for $10-20 \mathrm{~s}$, the absorbance
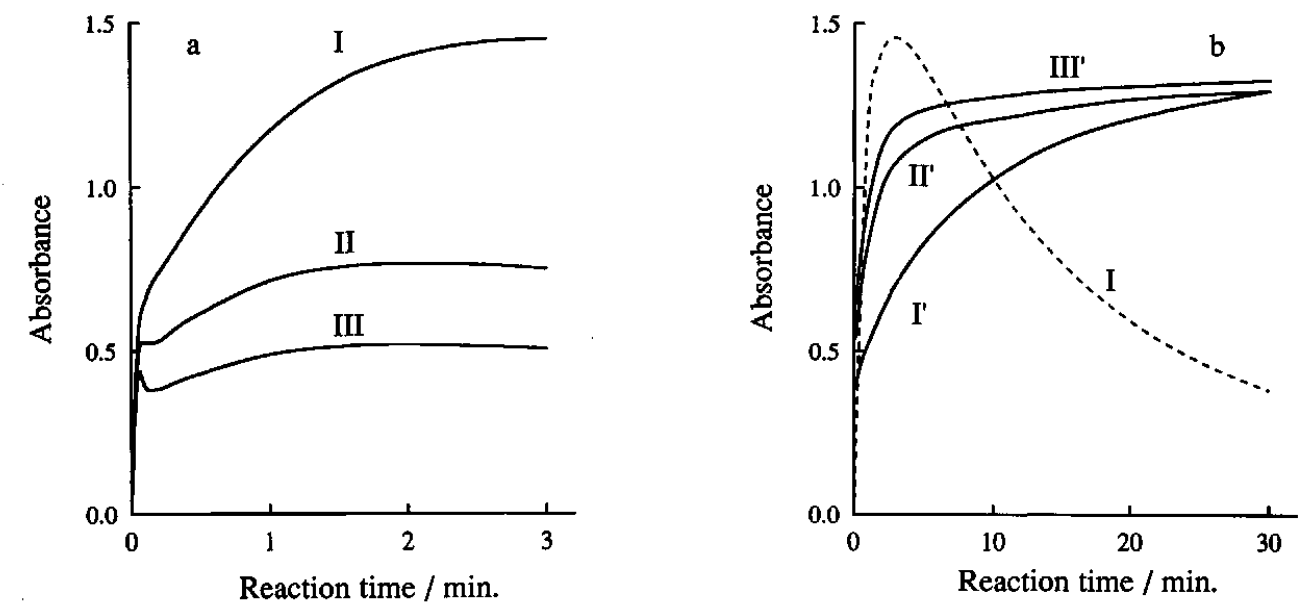

Fig. 1 Absorbance/time curves for the CP-hydrogen peroxide reaction in the presence of iron(II). Concentrations of tungsten(VI) $\left(\mu \mathrm{gl}^{-1}\right)$ : (I), (I') 0; (II), (II') 100; (III), (III') 200. Conditions as in the recommended procedure $\left(7.6 \times 10^{-2} \mathrm{M}\right.$ hydrochloric acid, $4.9 \times 10^{-3} \mathrm{M}$ hydrogen peroxide, $2.5 \times 10^{-4} \mathrm{M} \mathrm{CP}, 1.4 \times 10^{-4} \mathrm{M}$ iron(II), $35^{\circ} \mathrm{C}$ ). Wavelength: (I), (II), (III) $525 \mathrm{~nm}$; (I'), (II'), (III') $344 \mathrm{~nm}$. 
decreased rather slowly. The maximum absorbance decreased with an increase in the tungsten(VI) concentration (curves II and III), this value was thus used as a parameter for the tungsten(VI) determination. The reaction time required for the absorbance at $525 \mathrm{~nm}$ to reach the maximum decreased slightly with increasing tungsten(VI) concentration; the absorbances of blank, 100 and $200 \mu \mathrm{g} \mathrm{l}^{-1}$ tungsten(VI) solutions reached the maxima at 180,130 and $120 \mathrm{~s}$ after initiating the reaction, respectively.

In sulfuric acid medium, tungsten(VI) accelerates the direct sulfoxide formation reaction ${ }^{5}$, which could be followed by measuring the absorbance at $344 \mathrm{~nm}$. When the reactions shown in Fig. 1a were followed at $344 \mathrm{~nm}$, the higher the tungsten(VI) concentration, the higher the reaction rate $\left\{\right.$ Fig. $1 \mathrm{lb}$ (curves $\mathrm{I}^{\prime}$, II' and III')\}. In hydrochloric acid solution, tungsten(VI) acted as catalyst for the sulfoxide formation reaction as well as in sulfuric acid. It was thus considered that the amount of CP consumed by the direct sulfoxide formation reaction increased and the amount of CP available for colorformation therefore decreased with an increase in tungsten(VI) concentration, which may result in a lower maximum absorbance value at $525 \mathrm{~nm}$.

\section{Effect of the reaction temperature}

The influence of temperature on the maximum absorbance for both blank and tungsten(VI) solutions was studied in the $20-45^{\circ} \mathrm{C}$ range under conditions otherwise the same as in the recommended procedure (Fig. 2, $\mathbf{\Delta}, \mathbf{\Delta}$, O). The values of the blank solution remained approximately constant, while those for the tungsten solution rose slightly at temperatures higher than $40^{\circ} \mathrm{C}$. A temperature $35^{\circ} \mathrm{C}$ was chosen for further work because of the convenience for adjusting the temperature throughout the year and the reduction in time required for a single determination; the time required for the absorbance to reach a maximum decreased with increasing temperature from $600 \mathrm{~s}$ at $20^{\circ} \mathrm{C}$ to $180 \mathrm{~s}$ at $35^{\circ} \mathrm{C}$ for blank solution. The influence of temperature for the initial reaction rate method $^{5}$ was also shown in Fig. $2(\square, 0)$. It is obvious that the maximum absorbance method is superior to the initial reaction rate method $^{5}$ in this point.

\section{Effect of the reactant concentrations}

The effect of $\mathrm{CP}$ concentration was studied in the range $1.0 \times 10^{-4} \mathrm{M}-4.0 \times 10^{-4} \mathrm{M}$. As shown in Fig. 3a, the maximum absorbance of both blank and tungsten(VI) solutions increased with an increase in CP concentration. The sensitivity of this method, which is the difference in the value between blank and tungsten(VI) solutions, also increased with increasing CP concentration. However, the higher CP concentration was not very favorable, since the maximum absorbance of the blank solution became too high. The CP concentration of $2.5 \times 10^{-4} \mathrm{M}$ was selected; it gave around 1.5 of the maximum absorbance value of the blank solution. Figure $3 \mathrm{~b}$ shows that there is a complicated relation between the hydrogen peroxide concentration and the maximum absorbance.

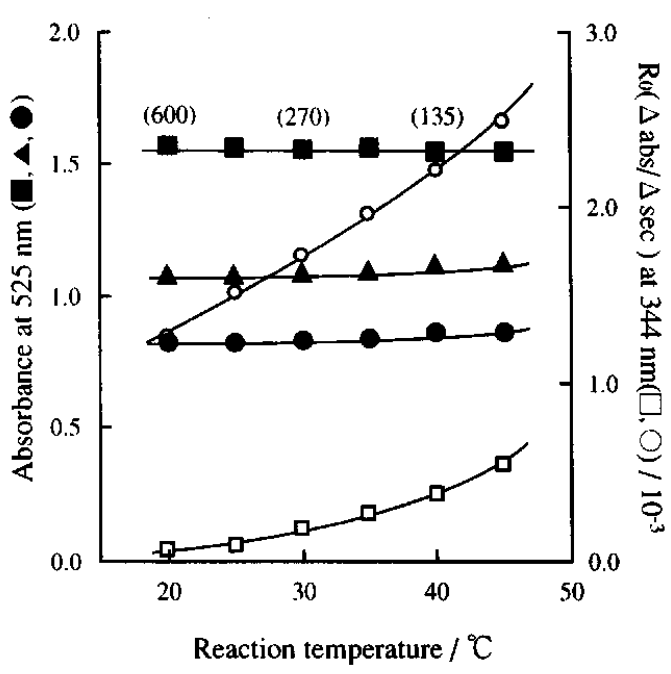

Fig. 2 Effect of the reaction temperature. Concentrations of tungsten(VI) $\left(\mu \mathrm{g} \mathrm{l}^{-1}\right)$ : ( $(\square),(\square) 0 ;(\Delta) 50 ;(O),(O) 100$. Times in seconds given in parentheses are those required for the absorbance for blank solution to reach a maximum. Conditions: ( $\square),(\Delta)$ and $(\Theta)$ as in Fig. 1, except for the reaction temperature; $(\square)$ and $(O)$ as in the recommended procedure of initial rate method (see reference 5), except for the reaction temperature.

The maximum absorbance value of the blank solution showed maximum at $4.9 \times 10^{-3} \mathrm{M}$ hydrogen peroxide, whereas the values of the tungsten(VI) solutions showed minima at $3.9 \times 10^{-3} \mathrm{M}$. A hydrogen peroxide concentration of $4.9 \times 10^{-3} \mathrm{M}$ was chosen, since it gave the highest sensitivity. The maximum absorbance values of tungsten(VI) solutions increased with an increase in hydrochloric acid concentration over the investigated range of $3.5 \times 10^{-3} \mathrm{M}-1.5 \times 10^{-1} \mathrm{M}$, whereas the value of the blank solution did not change significantly at concentrations higher than $7.6 \times 10^{-2} \mathrm{M}$ (Fig. 3c). Thus a hydrochloric acid concentration of $7.6 \times 10^{-2} \mathrm{M}$ was chosen. As can be seen in Fig. 3d, the maximum absorbance values of both blank and tungsten(VI) solutions increased with an increase in iron(II) concentration and at concentrations higher than $1.4 \times 10^{-4} \mathrm{M}$ and $2.1 \times 10^{-4}$ $M$, respectively, the values did not change significantly. An iron(II) concentration of $1.4 \times 10^{-4} \mathrm{M}$ was selected. As shown in Fig. 3 (a-d), the time required for the absorbance to reach a maximum increased with increasing CP concentration and decreased with increasing hydrogen peroxide, hydrochloric acid and iron(II) concentrations.

\section{Calibration and reproducibility}

A series of standard solutions of tungsten(VI) was treated as in the recommended procedure. The resulting graph is shown in Fig. 4. The relative standard deviations for 10 replicate determinations of 100,20 and $6 \mu \mathrm{g} \mathrm{l}^{-1}$ tungsten(VI) were $0.7,0.2$ and $1.7 \%$, respectively; the values were $8 \%$ and $0.6 \%$ at concentrations 2 and $500 \mu \mathrm{g} \mathrm{l}^{-1}$, which were the lowest and the highest limits of 

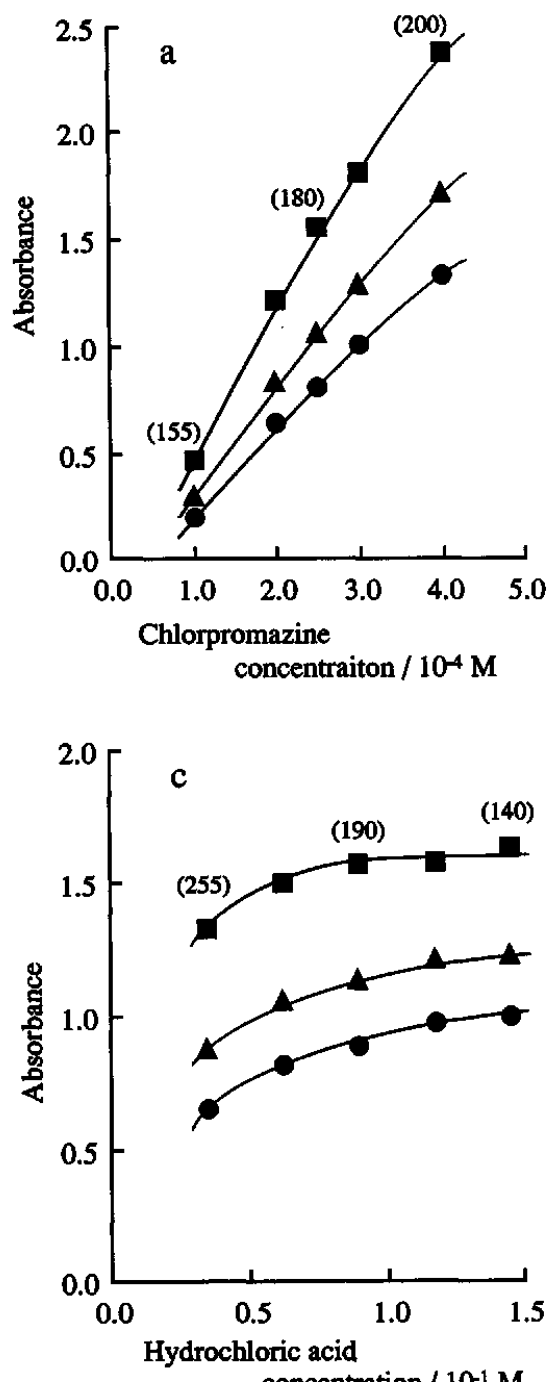
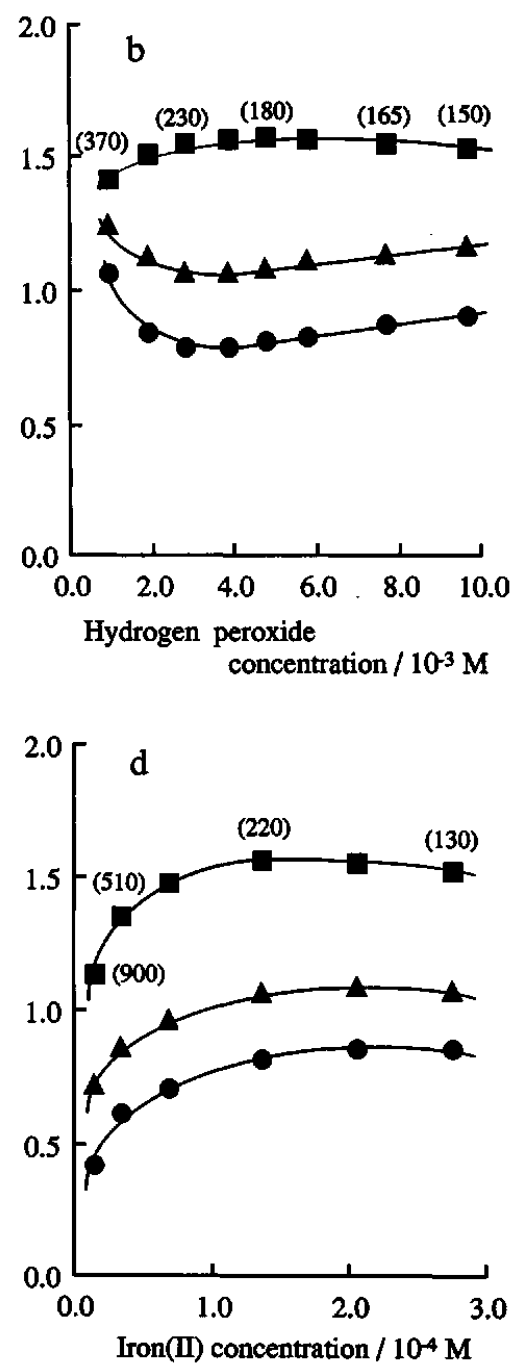

Fig. 3 Effect of the experimental variables [blank ( $\square), 50 \mu \mathrm{gl}^{-1}$ tungsten(VI) (A), $100 \mu \mathrm{g} \mathrm{l}^{-1}$ tungsten(VI) (๑)]: (a) chlorpromazine concentration, (b) hydrogen peroxide concentration, (c) hydrochloric acid concentration, (d) iron(II) concentration; times in seconds given in parentheses are those required for the absorbance for blank solution to reach a maximum. Conditions as in Fig. 1, except for the reagent indicated on abscissa.

determination, respectively. Tungsten(VI) in the range of $2-500 \mu \mathrm{g} \mathrm{l}^{-1} \mathrm{~W}$ (VI) can be determined by the proposed method with good reproducibility.

\section{Effect of other ions}

The effect of various ions on the determination of 0 and $50 \mu \mathrm{g} \mathrm{l}^{-1}$ tungsten(VI) was examined. The following ions showed no interference at the concentrations $\left(\mathrm{mg} \mathrm{l}^{-1}\right.$ ) shown in parentheses: $\mathrm{NO}_{3}{ }^{-}(1000) ; \mathrm{K}^{+}, \mathrm{CO}_{3}{ }^{2-}$ (500); $\mathrm{Cl}^{-}(400)$; $\mathrm{Ca}^{2+}, \mathrm{SO}_{4}{ }^{2-}(200)$; $\mathrm{As}(\mathrm{V}), \mathrm{Ce}^{3+}, \mathrm{Cr}^{3+}, \mathrm{Ni}^{2+}$, $\mathrm{Zn}^{2+}, \mathrm{Mg}^{2+}, \mathrm{Pb}^{2+}, \mathrm{Sr}^{2+}, \mathrm{Co}^{2+}, \mathrm{Ba}^{2+}, \mathrm{Cd}^{2+}, \mathrm{Mn}^{2+}, \mathrm{Hg}^{2+}, \mathrm{Li}^{+}$, $\mathrm{Na}^{+}, \mathrm{Br}^{-}, \mathrm{ClO}_{4}^{-}, \mathrm{ClO}_{3}{ }^{-}, \mathrm{BrO}_{3}^{-}, \mathrm{CH}_{3} \mathrm{COO}^{-}, \mathrm{SO}_{3}{ }^{2-}, \mathrm{PO}_{4}{ }^{3-}$ (100); $\mathrm{NH}_{4}^{+}(50) ; \mathrm{Sb}(\mathrm{V}), \mathrm{Se}(\mathrm{IV}), \mathrm{As}(\mathrm{III}), \mathrm{Fe}^{2+}(10)$; $\mathrm{Ce}^{4+}, \mathrm{Al}^{3+}, \mathrm{Cu}^{2+}, \mathrm{Ag}^{+}(5) ; \mathrm{Cr}(\mathrm{VI}), \mathrm{V}(\mathrm{V}), \mathrm{V}(\mathrm{IV}), \mathrm{Te}^{4+}, \mathrm{Sn}^{4+}$, $\mathrm{Sb}$ (III), $\mathrm{Fe}^{3+}, \mathrm{F}^{-}, \mathrm{S}_{2} \mathrm{O}_{3}{ }^{2-}(1)$. The interfering ions are listed in Table 1. Ions which are known to participate in redox reactions as either oxidizing or reducing agents
Table 1 Effect of interfering ions on the determination of 0 and $50 \mu \mathrm{g}^{-1}$ of tungsten(VI)

\begin{tabular}{lccc}
\multirow{2}{*}{ Ion added } & \multirow{2}{*}{ Concn. $/ \mathrm{mg} \mathrm{l}^{-1}$} & \multicolumn{2}{c}{ Tungsten(VI) found $\left(\mu \mathrm{g} \mathrm{l}^{-1}\right)$} \\
\cline { 3 - 4 } & & Blank & $50 \mu \mathrm{g} \mathrm{l}^{-1} \mathrm{~W}(\mathrm{VI})$ \\
\hline $\mathrm{SCN}^{-}$ & 1 & 27 & 140 \\
$\mathrm{NO}_{2}^{-}$ & 1 & 5.5 & 41 \\
$\mathrm{I}^{-}$ & 1 & 1.0 & 41 \\
$\mathrm{IO}_{3}^{-}$ & 1 & 1.0 & 44 \\
$\mathrm{Mo}(\mathrm{VI})$ & 0.1 & 24 & 73 \\
\hline
\end{tabular}

cause serious interference. Molybdenum(VI), which is one of the members of group VIA, seriously interferes. These ions showed no interference at concentrations one order of magnitude lower than those indicated in 
Table 2 Determination of tungsten(VI) in hot spring water samples

\begin{tabular}{|c|c|c|c|c|c|c|c|}
\hline Sample & Dilution/times & Added $/ \mu \mathrm{g}^{-1}$ & Found $/ \mu \mathrm{g} \mathrm{l}^{-1}$ & Recovery, \% & & \multicolumn{2}{|c|}{ In sample $/ \mu \mathrm{g} \mathrm{l}^{-1}$} \\
\hline \multirow[t]{8}{*}{ Hot spring water $\mathrm{I}^{\mathrm{b}}$} & - & - & 61.0 & - & & 61.0 & $60.9^{a}$ \\
\hline & 2 & - & 31.8 & - & & 63.5 & $60.4^{\mathrm{a}}$ \\
\hline & 2 & 10 & 39.5 & 95 & & & \\
\hline & 2 & 20 & 50.8 & 98 & & & \\
\hline & 5 & - & 12.8 & - & & 63.8 & $62.9^{\mathrm{a}}$ \\
\hline & 5 & 10 & 24.0 & 105 & & & \\
\hline & 5 & 20 & 31.8 & 97 & & & \\
\hline & & & & & ave. & 62.8 & $61.4^{\mathrm{a}}$ \\
\hline \multirow[t]{8}{*}{ Hot spring water $\mathrm{II}^{\mathrm{b}}$} & - & - & 55.8 & - & & 55.8 & $61.0^{\mathrm{a}}$ \\
\hline & 2 & - & 27.8 & - & & 55.6 & $60.2^{\mathrm{a}}$ \\
\hline & 2 & 10 & 38.0 & 101 & & - & \\
\hline & 2 & 20 & 48.0 & 100 & & - & \\
\hline & 5 & - & 11.4 & - & & 56.9 & $58.5^{\mathrm{a}}$ \\
\hline & 5 & 10 & 21.3 & 100 & & - & \\
\hline & 5 & 20 & 29.5 & 94 & & - & \\
\hline & & & & & ave. & 56.1 & $59.9^{\mathrm{a}}$ \\
\hline
\end{tabular}

a. Values obtained by initial rate method. ${ }^{5}$ b. Hot spring waters I and II were, respectively, collected at Onoaida and Kusugawa hot spring, Yaku island, Kumage. The location is in Kagoshima Prefecture, Japan.

Table 1. Iron(II) and iron(III), which interfered at $1 \mathrm{mg} \mathrm{l}^{-1}$ with the tungsten(VI) determination by the initial rate method, did not interfere up to 10 and $1 \mathrm{mg} \mathrm{l}^{-1}$, respectively.

\section{Determination of tungsten(VI) in hot spring water samples}

In order to test the reliability of the present method, it was applied to the determination of tungsten(VI) in hot spring water samples. The determinations were made by using samples diluted at different times. The method was also checked by adding a known amount of tungsten(VI) to the samples. The results are shown in Table 2. The values corrected for dilution showed good agreement, and good recoveries of added tungsten(VI) were obtained ranging from $94-105 \%$ (mean 99\%). Table 2 also shows the results obtained by the initial rate method, and the results obtained by proposed method agreed very closely with them.

The authors wish to thank Dr. Hayao Sakamoto and Mr. Katsuaki Hagie of Kagoshima University for giving them the hot spring water samples.

\section{References}

1. V. K. Pavlova, A. T. Pilipenko and R. N. Voevutskaya, Zh. Analit. Khim., 30, 2190 (1975).

2. R. N. Voevutskaya, V. K. Pavlova and A. T. Pilipenko, Zh. Analit. Khim., 34, 1299 (1979).

3. Z.-L. Jiang, L.-X. Liao and M.-D. Liu, Anal. Chim. Acta, 300, 107 (1995).

4. Z.-L. Zhu, C.-Q. Han, Z.-C. Gu and R.-M. Chen, Analyst [London], 119, 2251 (1994).

5. T. Tomiyasu, Anal. Chim. Acta, 312, 179 (1995).

6. T. Tomiyasu, H. Sakamoto and N. Yonehara, Anal. Sci., 8, 293 (1992)

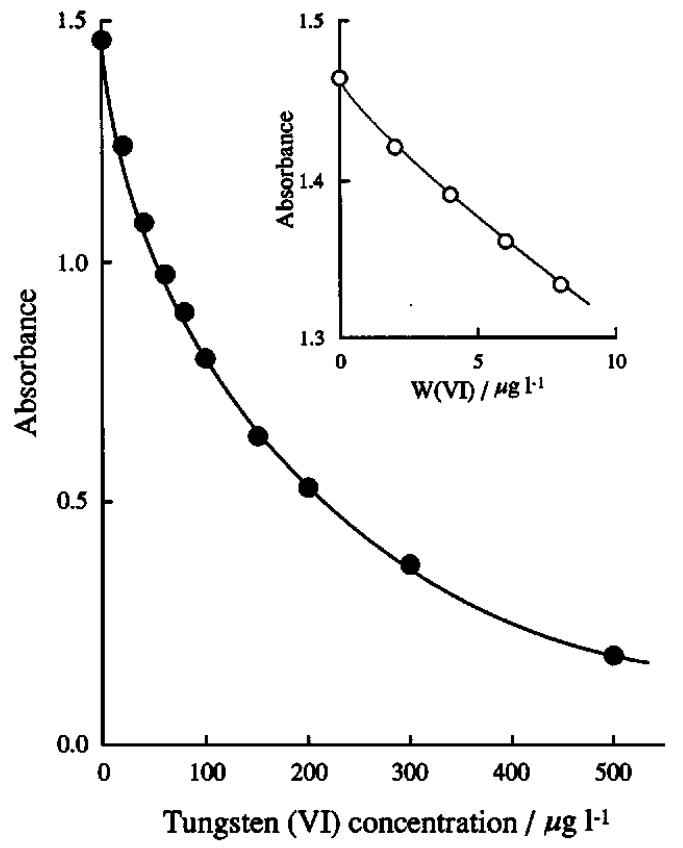

Fig. 4 Calibration graphs for the recommended procedure. Conditions as in Fig. 1. The inset provides details for the lower concentration range.

7. T. Tomiyasu, H. Sakamoto and N. Yonehara, Anal. Chim. Acta, 320, 217 (1996).

8. T. Tomiyasu, H. Sakamoto and N. Yonehara, Anal. Sci., 10, 761 (1994).

9. H. S. Gowda and R. Shakunthala, Talanta, 13, 1375 (1966).

(Received July 15, 1996)

(Accepted September 2, 1996) 